\title{
AÇÕES AFIRMATIVAS NA EDUCAÇÃO SUPERIOR: RUMOS DA DISCUSSÃO NOS ÚLTIMOS CINCO ANOS ${ }^{1}$
}

\author{
Fernanda Vieira Guarnieri \\ Lucy Leal Melo-Silva \\ Universidade de São Paulo, São Paulo, Brasil
}

\begin{abstract}
RESUMO: Aç̃̃es Afirmativas são medidas que visam à democratização do acesso ao emprego e à educação. Nas universidades brasileiras essas ações constituem programas de cotas para a inserção de grupos sociais com histórico de exclusão. No entanto a questão torna-se complexa quando são levantados critérios étnicos para sua definição. O objetivo do presente estudo, de revisão da literatura - do tipo estado da arte - é contribuir para a discussão no cenário brasileiro sobre as ações afirmativas no Ensino Superior a partir do levantamento do estado da arte nos últimos cinco anos. Foram utilizadas bases de dados eletrônicas (SCOPUS e Jstor); e os dados tratados conforme a Análise de Conteúdo de Bardin (1977). Os resultados foram organizados em três unidades de análise: (a) dicotomia entre artigos a favor ou contra as medidas; (b) enriquecimento do debate sobre "diversidade"; e (c) visualização dialética, mais integrada e reflexiva. Os achados contribuem para a compreensão da situação brasileira no cenário atual de proposição de políticas públicas na Educação Superior.
\end{abstract}

PALAVRAS-CHAVES: Estado da arte; ação afirmativa; educação superior.

\section{AFFIRMATIVE ACTION IN HIGHER EDUCATION: ROUTES OF DISCUSSION IN THE LAST FIVE YEARS}

ABSTRACT: Affirmative actions are social measures that seek to democratize the access to jobs and education. In Brazilian higher education, those actions consist of programs of vacancy quotes in universities for historically excluded social groups. The issue is complex in relation to defining ethnical and/or social criteria. The aim of this article, using state-of-art literature review, is to contribute in the discussion about affirmative action in Brazilian higher education, based on the survey of the state of the art in the last five years. Electronic data bases were used (SCOPUS and Jstor) and Bardin's (1977) content analysis was carried out. The results were organized into three analysis units: (a) a dichotomy existing between articles for and against the measures; (b) improvement on the debate about "diversity"; and (c) a dialectical, more integrated and reflective view. The findings contributed for elucidating the current state of Affirmative Action in the Brazilian context of devising public policies for higher education.

KEYWORDS: State-of-art; affirmative action; higher education.

As Ações Afirmativas podem ser compreendidas como medidas de caráter social que visam à democratização do acesso a meios fundamentais - como emprego e educação - por parte da população em geral. O principal objetivo destas medidas consiste em promover condições para que todos na sociedade possam competir igualmente pela conquista de tais meios. No Brasil as ações afirmativas são representadas essencialmente enquanto programas de cotas, isto é, são medidas que priorizam a inserção social de grupos minoritários com histórico de exclusão (étnicos, raciais, sexuais, entre outros) por meio da reserva de vagas.

A discussão acerca da implantação de medidas de Ação Afirmativa vem tendo relativa abertura na sociedade, no entanto a questão torna-se complexa quando são levantados critérios étnicos para a definição das mesmas. Em novembro de 2005 , representantes dos movimentos ne$\operatorname{gros}^{2}$ no Brasil, juntamente com entidades estudantis realizaram um apelo de urgência urgentíssima (Universia Brasil, 2002) em sessão extraordinária na Câmara dos
Deputados com a finalidade de proceder à votação do Projeto de Lei (n $\left.n^{\circ} 3627 / 2004\right)$ : "Sistema Especial de Reserva de Vagas", que institui cotas nas universidades públicas federais.

O referido projeto de lei institui reserva de vagas para estudantes que tenham cursado o ensino médio em escola pública e em especial para pessoas negras e indígenas nas instituições públicas federais de Educação Superior. A priorização étnica desses povos se dá pela justificativa de que as vagas não são preenchidas por negros e membros das comunidades indígenas em função de insuficiências circunstanciais desses grupos. A porcentagem das vagas reservadas para cada etnia corresponderia ao critério de composição étnica da população estadual sugerida pelo levantamento do último censo do Instituto Brasileiro de Geografia e Estatística (IBGE), de modo que os percentuais mínimos para negros e indígenas estarão de acordo com o perfil da população da unidade da Federação onde está a universidade (Ministério da Educação, 2006). 
Não obstante, a implantação de medidas desse tipo gera polêmica uma vez que a ênfase dada a questões étnicoraciais nos remete à constituição de uma identidade brasileira marcada pela valorização da mestiçagem. No entanto, se por um lado reservar vagas para negros e povos indígenas parece estimular animosidades geradas pela definição étnica, por outro devem ser considerados os prejuízos sociais causados pelo silente preconceito à brasileira e pela baixa representatividade dessas populações na produção de conhecimento. Portanto, para que se possa debater a questão das ações afirmativas para grupos étnicos específicos no Brasil é necessário o aprofundamento nas problemáticas relacionadas à definição de seus beneficiários e na releitura da identidade nacional de culto à miscigenação.

Políticas de igualdade racial como a ação afirmativa, ao exigirem direitos coletivos e a identificação racial dos grupos beneficiados, perturbam não apenas a noção moderna de igualdade e justiça, segundo o qual a distribuição de bens e posições sociais seria baseada no indivíduo e em seus méritos e talentos naturais, mas também a ideologia brasileira de mestiçagem e da democracia racial, constitutiva de nossa identidade e unidades nacionais onde não haveria espaço para divisões ou diferenciações de raça (Moehlecke, 2004a, p. 8).

Nesse sentido, em função do pioneirismo norte-americano no uso de ações afirmativas enfaticamente raciais, é esperado que os estudos realizados nos Estados Unidos sirvam de referência na compreensão histórica desse tipo de intervenção governamental, devendo ser salientadas as peculiaridades no posicionamento frente à segregação racial nos EUA. Desse modo, a implantação de medidas de ação afirmativa requer a compreensão do contexto sócio-histórico de cada país.

No Brasil, o segregacionismo embora não declarado, é cultuado socialmente de maneira silenciosa, mas não menos cruel. A discriminação racial no Brasil encontra meios informais de propagação e é dificilmente assumida. Com isso, a releitura do problema permite que as questões étnicas tanto nos EUA quanto no Brasil possam ser reavaliadas de acordo com o cenário social da pós-modernidade e analisadas as propostas de ação do governo.

Embora o ideal de multi-racialidade brasileira corrobore uma postura nacional vanguardista de referência para estudos internacionais (Maffesoli, 2002), o que tem chamado atenção é a forma como outra frente ideológica vem se opondo a esta concepção, voltando-se para definições étnico-raciais como início de um processo de reconhecimento e exposição do "racismo à brasileira" e suas consequiências negativas sobre a democratização de oportunidades no Brasil. Neste estudo, e de acordo com Ianni (2004b), os conceitos de raça e etnia são compreendidos em seus distintos significados.
A raça não é uma condição biológica como a etnia, mas uma condição social, psicossocial e cultural, criada, reiterada e desenvolvida na trama das relações sociais, envolvendo jogos de forças sociais e progressos de dominação e apropriação. Racionalizar uns e outros pela classificação e hierarquização revela-se, inclusive, uma técnica política, garantindo a articulação sistêmica em que se fundam as estruturas de poder. Racializar ou estigmatizar o 'outro' e os 'outros' é também politizar as relações cotidianas, recorrentes, em locais de trabalho, estudo e entretenimento; bloqueando relações, possibilidades de participação, inibindo aspirações, mutilando práxis humanas, acentuando a alienação de uns e outros, indivíduos e coletividades (p. 23).

Para que fosse possível angariar respaldo do tema enquanto questão fundamental a ser discutida pela sociedade em geral, frentes do movimento negro no Brasil, Universidades e grupos de discussão têm-se engajado no desenvolvimento de pesquisas capazes de retratar a realidade cruel ocultada pela beleza do discurso miscigenador do povo brasileiro. Assim, existem hoje consistentes pesquisas e investigações sobre o tema. As mesmas baseiam-se em argumentações sustentadas em teorias e práticas ou experiências vigentes em outros países com a finalidade de reivindicar políticas afirmativas para negros e povos indígenas no ensino superior brasileiro. Alguns desses argumentos evidenciam pontos críticos referentes às implicações sociais da educação superior.

"Parece que um número crescente de pessoas está disposto a renortear sua existência, a não mais tolerar seu alijamento do processo histórico e a retornar a pergunta fundamental a respeito do sentido da vida, individual e coletiva" (Goergen, 2005, p. 7).

Nesse sentido, enfatizam-se reflexões essenciais sobre a elitização das Universidades Públicas Brasileiras, assunto que vem sendo retomado e rediscutido, de modo a relacionar as consequiências da escassa representatividade de negros e povos indígenas na Universidade com a incipiente mobilização do interesse acadêmico para produção científica consistente que vise melhorar a situação de grupos sociais em situação de desvantagem. Outra questão vinculada ao estabelecimento de estratégias de inserção na Educação Superior incide sobre os critérios atuais dos exames vestibulares que reafirmam a valorização do mérito individual e desconsideram os efeitos discriminatórios na formação educacional, desde o início da escolarização.

Especificamente sobre duas das etnias brasileiras, a saber: a indígena e a negra, a historicidade do processo civilizatório deve ser retomada para a compreensão do presente. No primeiro caso, escravizados por estrangeiros na própria terra natal, colonizados e coagidos em suas tradições culturais e espirituais, muitas famílias indígenas suicidaram-se como forma de resistência à dominação 
imposta pelos europeus. Em outros casos, pela resistência ao trabalho escravo, muitos chefes de família indígena foram assassinados, expondo suas mulheres e filhos às mais diversas formas de violência sexual, física e moral. Isso sem mencionar os massacres dos povos indígenas, quer por doenças trazidas pelos europeus (como varicela, escarlatina, varíola, sarampo, gripe e tuberculose), quer por exércitos portugueses e espanhóis (Potiguara, 2002).

Já os negros africanos surgiram como alternativa de reposição de mão-de-obra escrava nas lavouras de cana de açúcar. Afastados de suas raízes culturais, pela violência com que foram segregados de seu nicho, foram coagidos a deixarem em seu país de origem, costumes, crenças, religiosidade e laços familiares. Dessa forma, durante a escravidão, foram transformados em povos desacreditados, identificados como animais de tração. Mesmo diante das adversidades - favorecidas pelo cenário colonial como as perseguições, açoites e violenta imposição da supremacia européia mesmo após a abolição da escravatura os povos africanos, a duras penas, tiveram de resgatar as próprias singularidades, criando clandestinamente as ferramentas necessárias para a sua construção enquanto ser humano.

Ao se destituir um povo de história, na medida em que suas peculiaridades são desconsideradas, o passado é esquecido e a compreensão do presente torna-se fragmentária e é prejudicada. É nesse sentido que representantes dos movimentos negros e indígenas, no Brasil, contestam a harmonia mestiça em contraposição à óbvia constatação do preconceito construído historicamente contra etnias negras e indígenas. Diante de tais questionamentos, tornase essencial o acompanhamento das discussões sobre esse assunto, ainda bastante controverso, não só no Brasil como em outros países adotantes ou não de medidas preferenciais. Em estudo recente, Moehlecke (2004a) constatou que mesmo nos EUA, depois de 30 anos de vigência de políticas sensíveis à raça no ensino superior, apenas a partir dos anos 90 foram realizados estudos sobre o impacto dessas políticas no ensino superior.

Assim sendo, o presente estudo, de revisão da literatura, busca trazer contribuições para a discussão sobre o tema no cenário brasileiro a partir da sistematização das informações referentes às ações afirmativas voltadas ao Ensino Superior disponíveis em indexadores online. Com isso pretende-se identificar algumas das linhas de pensamento que têm permeado essa discussão nos últimos cinco anos.

\section{Método}

Este artigo, sobre as ações afirmativas na Educação Superior, consiste em um estudo de revisão da literatura, tipo estado da arte, que analisa um corpo de conhecimento relativo a essa temática. Estudos dessa natureza são de caráter exploratório e contribuem enquanto importantes parâmetros para entendimento da evolução em produção científica sobre determinado tema. De acordo com Soares (citado por Ferreira, 2002), a organização periódica do conjunto de informações e resultados já obtidos favorece a orientação das "possibilidades de integração de diferentes perspectivas, aparentemente autônomas, a identificação de duplicações ou contradições, e a determinação de lacunas e vieses" (p. 259). Sob esse enfoque, os dados deste estudo foram obtidos a partir dos resumos de publicações científicas disponíveis em bases de dados eletrônica. Optou-se por bancos de dados virtuais, pelo fato de possibilitarem o acesso a pesquisas mais recentes sobre $o$ tema. Trata-se, portanto, de um estudo descritivo e não exaustivo, sujeito aos filtros perceptuais dos autores e às limitações de estudos desta natureza, visto que foram utilizados os resumos das publicações. Assim sendo, o percurso metodológico para a obtenção e análise dos dados é descrito a seguir.

\section{Percurso metodológico e obtenção dos dados}

Os debates travados em torno das medidas de ação afirmativa que visam à implementação de Cotas Universitárias são de interesse das ciências sociais e humanas. Considerando que a prática brasileira em Orientação Profissional, especialmente em contextos psicológicos e/ou educativos, desenvolveu-se voltada a estudantes que aspiram à carreira universitária (Melo-Silva, Lassance \& Penna, 2004), esse debate é relevante para pesquisadores das áreas da Psicologia, na qual se inserem os autores deste artigo.

Assim sendo, o percurso inicial de aproximação ao tema, conduziu à busca de estudos na literatura que relacionassem as ações afirmativas à escolha de carreira universitária, objetivando verificar possíveis influências e desdobramentos dessas ações no comportamento de escolha profissional. Esse foi o critério inicial para obtenção dos dados da literatura. A priori o objetivo consistia em levantar a bibliografia nacional sobre o tema, dando-se preferência pelas publicações na área da Psicologia. Para tal, foram realizadas buscas na Biblioteca Virtual em Saúde (BVS-PSI), que abrange estudos de 24 diferentes países latinos. Na busca inicial, forma utilizados os descritores ação afirmativa e escolha da carreira ou carreira, e suas versões em inglês affirmative action e career choice ou career. Não foram encontrados trabalhos sobre a influência das ações afirmativas sobre o comportamento de escolha da carreira nas fontes consultadas.

Definiu-se, portanto, pela realização de um estudo exploratório que focalizasse as ações afirmativas no contexto do ensino superior. Para tal, utilizou-se os descritores affirmative action $\mathrm{e}$ higher education ou university. A seguir, optou-se pela utilização de duas bases de dados que pudessem contribuir de maneira mais significativa à 
busca bibliográfica pretendida. Foram selecionadas as bases SCOPUS e Jstor, pela expressividade do acervo de trabalhos na área das Ciências Sociais e pela grande quantidade de publicações pertinentes ao objeto de estudo em foco. A base de dados SCOPUS possui cerca de $27 \mathrm{mi}-$ lhões de resumos, incluindo citações, desde 1996. É considerado um dos maiores bancos de dados disponíveis nas redes eletrônicas. É uma base completa e de acesso limitado às Instituições de Ensino conveniadas. No Brasil, até o presente momento tal parceria se restringe apenas às seguintes instituições brasileiras: Universidade de São Paulo (USP), Universidade do Estado de São Paulo (UNESP) e Universidade de Campinas (UNICAMP). A base de dados Journal Store (Jstor) é definida como uma organização sem fins lucrativos, tendo como finalidade criar e manter um arquivo confiável de importantes periódicos do meio acadêmico, facilitando o acesso de modo a oferecer aos pesquisadores a possibilidade de recuperar conteúdos em formato original na própria página, como por exemplo: figuras, ilustrações, tabelas, etc. (Journal Store, 2000). Seu acervo consta de coleções multidisciplinares e de disciplinas específicas.

Posteriormente, a fim de delimitar o campo de análise foram definidos os critérios de seleção dos trabalhos: (a) aqueles cujas palavras-chaves encontravam-se tanto nos resumos quanto no corpo do texto, (b) publicação nos últimos cinco anos.

\section{Análise dos dados}

Os dados foram tratados com base na Análise de Conteúdo (Bardin, 1977), definida como: "um conjunto de técnicas de análise das comunicações, que utiliza procedimentos sistemáticos e objetivos de descrição do conteúdo das mensagens, indicadores (quantitativos ou não) que permitam a inferência de conhecimentos relativos às condições de produção/recepção (variáveis inferidas) destas mensagens" (p. 42). O pesquisador nesse processo deverá, a partir da leitura per se do material, realçar um sentido que se encontra "em segundo plano" (p. 41), através da inferência e da interpretação. Mais especificamente a técnica da análise de conteúdo utilizada foi do tipo Análise das Relações, que consiste basicamente na análise das co-ocorrências e na análise estrutural, com base no "procedimento de Osgood" (Bardin, 1977, p. 199).

As etapas de estudos dessa natureza desenvolvem-se em torno de três pólos: (a) a pré-análise; (b) a exploração do material; (c) o tratamento dos resultados - a inferência e a interpretação.

Neste estudo, a pré-análise consistiu na leitura flutuante dos resumos com a finalidade de estabelecer contato com o material. A exploração do material consistiu em hipóteses provisórias formuladas a fim de construir categorias de análise, temas centrais associados a alguns critérios estruturais dos estudos, como por exemplo, o tipo do estudo - teóricos, exploratórios e de acompanhamento/teórico-reflexivos -, as temáticas recorrentes e as principais teorias adotadas. Na etapa final, a partir da inferência e interpretação, os dados foram organizados em três unidades de análise, que representam três movimentos: (a) pensamento dicotômico contra ou a favor; (b) exploração de conceitos de diversidade e (c) reflexões dialéticas.

\section{Resultados e discussão}

\section{Resultados da pré-análise}

Foram encontrados 122 resumos, sendo 80 da base Jstor e os 42 restantes da SCOPUS. Com a finalidade de aprofundar a análise dos resumos encontrados, foram selecionados 59 resumos: oito da base Jstore 57 da SCOPUS, seguindo os critérios previamente estabelecidos: palavraschave no resumo e publicação nos últimos 5 anos.

Analisando a distribuição por ano dos resumos publicados, observaram-se picos de publicação nos anos 2000 e 2003, somando respectivamente 12 e 24 trabalhos publicados na base Jstor; e 11 e 12 na SCOPUS. Os periódicos encontrados foram: Chronicle of Higher Education (16), The Journal of Blacks in Higher Education (13), The Journal of Higher Education (5), Educational Policy (5), Social Science Quarterly (4), Western Journal of Black Studies (3), Advances in Education in Diverse Communities: Research, Policy and Praxis (3), Academic Medicine (3), Journal of Negro Education (3), American Educational Research Journal (2), Education Policy Analysis Archives (2), Industrial and Labor Relations Review (2), Journal of Dental Education (2), Journal of Social Issues (2), Research in Higher Education (2), American Sociological Review (1), British Journal of Middle Eastern Studies (1), Political Behavior (1), American Behavioral Scientist (1), American Journal of Education (1), Australian Psychologist (1), British Journal of Middle Eastern Studies (1), Comparative Education (1), Educational Evaluation and Policy Analysis (1), Harvard Educational Review (1), Harvard International Journal of Press/Politics (1), Hastings Law Journal (1), Higher Education Policy (1), International Journal of Educational Research (1), Journal of Adult Development (1), Journal of Education Policy (1), Journal of Law and Economics (1), Journal of Professional Nursing (1), Journal of the American Medical Association (1), Latin American Research Review (1), Organizational Behavior and Human Decision Processes (1), Policy Studies Journal (1), Political Geography (1), Psychological Science (1), Psychology, Public Policy, and Law (1), Public Opinion Quarterly (1), Review of Higher Education (1), Saludarte (1), Sociology of Education (1), UCLA Law Review (1), Urban Education (1), Urban Review. A grande maioria dos referidos periódicos é de origem norte-americana. Esse fato pode ser atribuído tanto pela expressiva produção cientifica desse país, quanto por uma preocupação maior em tratar do referido tema. 


\section{Resultados da exploração do material}

Com relação aos conteúdos, observou-se que em 2003 as pesquisas foram marcadas por alusões à atitude da Suprema Corte norte-americana de apoio e suporte à implantação das ações afirmativas nos cursos de medicina dos EUA (Bowen \& Rudenstine, 2003; Cohen, 2003). De maneira geral, as publicações explicitam a preocupação com levantamento de fatores positivos e/ou negativos associados às ações afirmativas, nos âmbitos legais, sociológicos e econômicos. Muitos trabalhos centraram-se na investigação das razões que fazem as populações afrodescendentes tão pouco representativas no Ensino Superior e as consequiências disto na sociedade como um todo. Vários estudos norte-americanos problematizaram o critério do Scholastic Assessment Test (SAT), sistema utilizado para admissão de estudantes nas universidades norte-americanas, que consistiria em um mecanismo centrado em critérios mais meritocráticos do que aristocráticos, com a finalidade de identificar estudantes promissores sem a utilização de determinantes econômicos, sociais ou étnicos (Moehlecke, 2004a). Nesse sentido, propõem reflexões sobre formas alternativas de seleção dos candidatos. A maioria dos estudos ressaltou a existência de demanda significativa de produção de conhecimentos para a solução de problemas na sociedade civil, associando-se à elitização das universidades a aparente falta de interesse dos estudantes por temáticas sociais e raciais.

\section{As três unidades de análise}

Pensamento Dicotômico "Contra" ou "A Favor". Essa primeira unidade de análise é caracterizada por revisões históricas, teóricas ou práticas referentes a medidas de ações afirmativas já implantadas. Os estudos categorizados nesta unidade de análise caracterizam-se tanto pelo dimensionamento da Ação Afirmativa como alternativa de promoção de Justiça Social e reparação histórica de efeitos discriminatórios (Anderson, 2002; Delgado \& Stefancic, 2000; Rhoads, Saenz \& Carducci, 2005) quanto por questionamentos sobre a incumbência estatal para esse tipo de política pública (Iygun \& Levin, 2003; Welsh, 2004). Constatou-se também a alta incidência de artigos trazendo problemáticas relativas à valorização do mérito individual em detrimento da adoção das políticas de ação afirmativa e a implantação das cotas na Universidade ou percentage plans (Long, 2003), utilizando como sustentação argumentativa as Teorias Cognitivistas de Desenvolvimento: quanto maior a constatação da crença pessoal dos estudantes em sua auto-eficácia (Wolff \& Wolff, 2005), maior a valorização da importância do mérito individual no ingresso à universidade e conseqüente des-sensibilização para formas alternativas de seleção (Guinier, 2003; Gurin, Dey, Hurtado \& Gurin, 2002; Zamani \& Brow, 2003).

Em relação ao tipo de estudo, de maneira geral, os estudos dessa unidade foram classificados como teóricos, ou seja, estudos marcados pela exploração de hipóteses e teorias acerca de influências a médio e longo prazo da implantação das cotas, no entanto sem enfatizarem um exemplo específico. Deve-se ressaltar a unilateralidade dos estudos, isto é, marcados por oposição ou defesa quanto à reserva de vagas. Outro aspecto observado foi a crítica aos testes de admissão (Hoffman \& Lowitzki, 2005), que direcionavam impasses gerados pela intervenção em Políticas Universais (caráter universal) para o favorecimento de Políticas Preferenciais (Detterman, 2000; Wightman, 2000).

Exploração de Conceitos de Diversidade. A segunda unidade de análise reúne trabalhos que enriquecem o debate sobre diversidade, a partir de intervenções diretas junto à população como, por exemplo, entrevistas com estudantes ou funcionários das Universidades sobre programas de ação afirmativa. Nesse grupo, os resumos foram analisados e categorizados como práticos ou exploratórios a partir de modelos experienciais de ação afirmativa, bem como suas possibilidades e desafios. Sobre a exploração da temática e do conteúdo das publicações selecionadas, foi possível identificar estudos que tratavam especificamente de aspectos da diversidade em contraposição a outros que evidenciavam questões sobre mérito individual, de tal forma que os primeiros pareciam trazer contribuições mais humanas de desenvolvimento ao considerar as diferenças percebidas desde o início da escolarização (Delgado \& Stefancic, 2000). De maneira semelhante, observou-se a recorrência de estudos mais detalhados sobre os efeitos positivos da diversidade no contexto escolar (Gurin, Nagda \& Lopez, 2004), dentre os quais aumento da conscientização política e da responsabilidade social (Massey, 2004); contribuição sobre o aumento do interesse nacional pelos problemas das minorias (Bollinger, 2003), além de favorecer o desenvolvimento cognitivo e os ganhos com a socialização e convívio com as diferenças (Anderson, 2002).

Reflexões Dialéticas - Integração de Contradições. A terceira unidade de análise explicita o movimento dialético, definido enquanto produções reflexivas sobre as ações afirmativas, sendo abordadas em uma perspectiva mais integrada e reflexiva sobre as consequiências para a sociedade de sua implantação nas Universidades. Tais estudos apresentaram maior preocupação com a pós-admissão dos alunos e as formas de internalização de conceitos de integração versus marginalização.

Nessa unidade predominam, portanto, estudos voltados para a pós-admissão de alunos pelo sistema de cotas, ou seja, investigação dos programas de suporte financeiro e cultural inseridos no contexto das instituições adotantes. Desse modo, investigou-se se tais programas estavam adequadamente integrados ao cotidiano universitário, e também quais os mecanismos adotados pelas Universidades para alterar os índices de evasão escolar da população de afro, cino e asio americanos (Cade, 2002). 
A grande maioria das publicações trata de estudos reflexivos, apresentando uma visão mais dialética, com objetivo de favorecer uma compreensão mais integrada, levando em conta as contradições e contra-sensos inerentes à temática. Desse modo foi possível constatar algumas tentativas de ampliação dessa perspectiva de maneira a abordar problemas e benefícios da implantação de modelos vigentes, fornecendo uma visão crítica voltada para a necessidade de se pensar identidades sociais em suas especificidades étnicas (Sonn, Bishop \& Humphries, 2000).

Outros estudos trouxeram relatos de estudantes beneficiados pelas cotas, os quais denunciaram o falso discurso de igualdade e democracia racial vigentes atualmente, sobretudo, nas universidades norte-americanas, sendo o mesmo utilizado de maneira estereotipada e pouco vista na prática (Sonn et al., 2000). Foram levantadas questões sobre alternativas para facilitar o processo de internalização da tolerância diante das diferenças em contraposição à anulação do arsenal simbólico, isto é, a padronização cultural e racial da reincidente sociedade colorblind (Bollinger, 2003).

Foi encontrado um estudo sobre o Brasil (Htun, 2004), o qual trouxe contribuições interessantes para a compreensão da dinâmica brasileira e seu modelo peculiar de movimentação social vista por outros países. De acordo com o referido estudo, os Movimentos Negros brasileiros - em contraposição aos modelos internacionais - consolidam-se a partir de princípios próprios, compartilhando pouco de seus ideais com a população em geral. Desse modo, organizam-se e direcionam-se diretamente ao Poder de Estado, ao qual se reivindica direitos que só poderão ser integrados por vias legais, a partir da participação da sociedade civil na criação de políticas públicas. O mesmo autor pontua que a ação afirmativa no Brasil representa o exercício dialético entre o movimento social e a iniciativa presidencial, que se organiza e é organizada a partir das repercussões internacionais sobre o tema.

\section{Considerações Finais}

De modo geral a produção científica em cinco anos de publicação - de 2000 a 2005 - sobre a temática permitiu que fosse verificada a existência de uma determinada dinâmica acerca da discussão sobre cotas no Ensino Superior, iniciando-se na defesa de princípios de Justiça Social e reparação histórica de efeitos discriminatórios e tendendo para questões mais direcionadas à promoção da Diversidade Cultural.

Desse modo pôde-se verificar que a expressiva quantidade de trabalhos tratando de temáticas raciais pode ser compreendida como tentativa de convocar a produção científica para a preocupação fundamental com a reconstrução de Identidades Sociais diversas em contraposição com a padronização de uma identidade única, oscilante entre critérios colorblind (Bollinger, 2003) e de taxonomia bipolar (Fry \& Maggie, 2004).

Ao lado de outros dilemas, também fundamentais, como as guerras religiosas, as desigualdades masculino-feminino, $o$ contraponto natureza $e$ sociedade $e$ as contradições de classes sociais [grifo do autor], a questão racial revela-se como um desafio permanente, tanto para indivíduos e coletividades como para cientistas sociais, filósofos e artistas (Ianni, 2004b, p. 21).

A partir da presente exposição pode-se verificar que a discussão sobre ação afirmativa, tanto nos EUA quanto no Brasil, oscila entre os três momentos, aqui definidos como unidades de análise, que explicitam as idéias expressas nas publicações analisadas. Entretanto, cumpre ressaltar que cada conjunto de idéias segue uma dinâmica peculiar. Em linhas gerais, no decorrer dos anos, o avanço da discussão nos EUA parece ter sido norteada pela seqüência dos três movimentos (unidades de análise).

No Brasil, somente a partir de 1990 as idéias acerca da implantação de ações afirmativas têm se tornado mais expressivas e persuasivas nos meios de comunicação de massa e rodas de discussão. Esse fenômeno se deu, em grande parte, pela mudança de postura do governo nacional, regida na época pelo presidente Fernando Henrique Cardoso, o que favoreceu modificações no tipo de ação política racial e no discurso oficial o que consequentemente norteou a busca sobre a essência das desigualdades aceitas na prática e negadas no discurso apaziguador da diversidade racial (Htun, 2004).

Nesse sentido, anteriormente a esse fato havia maior preocupação em se manter a cumplicidade nas relações colorblind (Bollinger, 2003) ou de valorização da mestiçagem - quer impostas, quer aceitas - dificilmente questionadas a partir da realidade social brasileira. Refere-se aqui a uma aceitação recíproca da existência de uma ambígua passividade/pacificidade na relação entre brancos e negros. São discursos sustentados por pensamentos vanguardistas que se posicionam em favor da mistura de cores e raças para a formação de uma sociedade "miscigenada". No entanto cabe ressaltar, como apontado por Htun (2004), que o papel assumido historicamente pelos governos brasileiros em se absterem da responsabilidade diante da discriminação racial teve repercussões negativas para a formação de uma sociedade autoconsciente e com iniciativa para ação coletiva.

Existe, portanto uma grande e histórica resistência brasileira em tratar da definição racial e do racismo para justificar as desigualdades nítidas entre oportunidades de negros e brancos na sociedade. Apresentam-se assim, discursos que culpabilizam os níveis sociais por tais disparidades. Trata-se, portanto de um recurso dissociativo entre relações sociais e relações raciais, descomprometendo-se 
o viés racial/étnico da estratificação da sociedade brasileira.

The racial democracy thesis... insists that the disproportionate impoverishment of blacks and their absence among elites is due to class discrimination and the legacy of slavery, and that the absence of statesponsored segregation, a history of miscegenation, and social recognition of intermediate racial categories have upheld a unique racial order (Htun, 2004, p. 64).

Desse modo, poderíamos situar essa valorização da mestiçagem, vista como integradora da diversidade, como referente ao $2^{\circ}$ movimento categorizado nesse estudo. Recentemente, porém, com a iminência da votação do Projeto de Lei Federal que prevê a adoção de sistemas especiais de reserva de vagas, a sociedade em geral parece ter sido surpreendida pela reivindicação de definição étnico-racial. Com isso, percebe-se uma tendência a discursos defensivos "contra" ou "a favor", caracterizados pelo $1^{\circ}$ movimento. Nesse sentido, o conceito de ancoragem, desenvolvido pela Psicologia Social no âmbito das representações sociais, permite identificar o $1^{\circ}$ movimento como tendência de resposta dicotômica esperada em situações em que envolvem a "dificuldade em aceitar o estranho e o diferente... percebido como 'ameaçador"'(Strey et al., 1998, p. 109), como é o caso do tabu racial brasileiro.

No caso brasileiro, a definição de cotas para negros, segundo Ianni (2004a), aparece num primeiro momento como conquistas sociais dos movimentos negros, mas também pode ser vista como concessões dos donos do poder, a reiteração de uma sociedade injusta, fundada no preconceito. "Ela é tão evidentemente fundada no preconceito que é preciso estabelecer espaços bem determinados e limitados para que eles tenham a possibilidade de participação" (Ianni, 2004a, p. 16). Por outro lado, há posições que defendem a implementação de ações corretivas para sanar a situação de desigualdades raciais, que são produto de circunstâncias sociais, históricas e contemporâneas e de conjunturas econômicas educacionais e políticas (Melo-Silva et al., 2004).

Com base nos estudos sobre o genoma humano podese afirmar que o conceito de raça não tem pertinência biológica, porém "a pigmentação da pele ainda parece ser um elemento predominante de avaliação social do indivíduo e talvez a principal fonte de preconceito" (Pena $\&$ Bortolini, 2004, p. 46). Portanto, o problema é político. E se há desigualdades sociais e educacionais cabe ao Governo e a sociedade buscar caminhos para o enfrentamento do problema por meio de políticas públicas compensatórias. $\mathrm{E}$ esse movimento no Brasil de arrasta há décadas.

"O primeiro registro do que chamamos de ação afirmativa data de 1968, quando o Ministério do Trabalho manifestou-se em favor da criação de uma lei que obri- gasse empresas privadas a contratarem uma porcentagem de empregados negros" (Moehlecke, 2004b, p. 758).

Se por um lado medidas compensatórias levam os mais negativistas a argumentarem que se trata de um retrocesso para as ciências humanas, por outro lado, os mais otimistas defendem a alternativa que, se bem explorada, poderá favorecer o processo de re-significação da experiência de ser negro no Brasil. Isso se for conciliado a esse processo a conscientização crítica diante da constatação de desigualdades raciais em um cenário contemporâneo que parece ignorar a existência de problemas - como os de marginalização racial e social - e buscar possibilidades na prática para enfrentamento do mesmo.

Moehlecke (2004b), no excerto a seguir, justifica o porquê da importância e da atualidade de posturas construídas diante de diferentes grupos sociais em relação às políticas públicas:

... das Luzes e da Modernidade foram excluídos os índios, os escravos e os povos colonizados, que não compartilhavam da natureza humanizada dos chamados homens, e também as mulheres, supostamente incapazes, assim como as crianças, de fazerem uso da razão nos assuntos públicos. Declarações de direito eram proclamadas ao mesmo tempo em que franceses e norte-americanos escravizavam grande parte da população negra mundial (p. 761).

Tais marcas históricas devem ser consideradas e trabalhadas na medida em que ainda hoje, quando se tornou tão arcaico retornarmos a questões como o racismo, é necessária a busca por recursos que auxiliem a compreensão da pluralidade perdida no processo de massificação do homem construído sem o rastro de sua formação e história. Desse modo, reivindica-se um novo olhar sobre a mestiçagem brasileira, questionando-se se a mesma compartilha da tolerância, aceitação e autocrítica diante de divergências plurais do ser humano.

Nesse percurso atravessado por vivências, o estigmatizado desenvolve sua percepção, sensibilidade; construindo e reconstruindo a sua consciência no contraponto do 'eu' e do 'outro', do 'nós' e do 'eles', dos 'subalternos' e dos 'dominantes'. Assim aos poucos, ou de repente, realiza um entendimento mais amplo e vivo de qual é sua real situação, quais são os nexos do tecido social no qual está emaranhado, de como essa situação implica decisivamente a ideologia e a prática dos que discriminam. Esse é o percurso em que se desenvolve a consciência crítica, a autoconsciência ou a consciência para si, reconhecendo que é desde essa autoconsciência crítica que nasce a transformação, a ruptura ou a transfiguração (Ianni, 2004b, p. 25).

Nesse sentido, as questões tratadas pelo presente estudo sobre ações preferenciais em âmbito internacional tornamse complementares para contextualização do debate bra- 
sileiro na atualidade. As questões contraditórias das ações afirmativas - no caso, as cotas universitárias - devem ser consideradas e enfrentadas enquanto experiência de valorosa contribuição para o debate sobre a implantação de medidas estatais brasileiras que regulem, nas adversidades, a apropriação do direito a meios fundamentais por grupos com histórico de exclusão.

Em síntese, conclui-se que discussões envolvendo etnicidades, pertença social e responsabilidades por mudanças, longe de se tratarem de assuntos superados, tornamse essenciais para formação de uma sociedade mais tolerante e democrática na medida em que for possível o convívio com as diferenças, sem que para isso seja necessária a padronização da grande capacidade subjetiva do ser humano: conciliar-se com a heterogeneidade do coletivo, sem abrir mão de sua individualidade.

\section{Notas}

1 Este artigo apresenta uma revisão da literatura relativa ao projeto de pesquisa de Mestrado, realizado pela primeira autora com bolsa FAPESP, e orientado pela segunda autora.

2 Optou-se pela definição de "movimento negro" no plural em decorrência da diversidade de sua formação ideológica no contexto brasileiro. Tal diversidade acaba por repercutir em divergências de posicionamento frente à adoção de programas de cotas para afrodescendentes.

\section{Referências}

Anderson, E. (2002). Integration, affirmative action, and strict scrutiny. New York University Law Review (NYU Law Review), 77, 11951271.

Bardin, L. (1977). Análise de conteúdo (L. A. Reto \& A. Pinheiro, Trad.). Lisboa, Portugal: Edições 70.

Bollinger, L. C. (2003). The need for diversity in higher education. Academic Medicine, 78(5), 431-436.

Bowen, W. G., \& Rudenstine, N. L. (2003). Race-sensitive admissions: Back to basics. The Chronicle of Higher Education, 1-21.

Cade, A. P. (2002). Affirmative action in higher education. Education Policy Analysis Archives, 10(22). Retirado em 26 maio 2006, de http://epaa.asu.edu/epaa/v10n22.html.

Cohen, J. J. (2003).The consequences of premature abandonment of affirmative action in Medical School Admissions. Journal of the American Medical Association (JAMA), 289, 1143-1149.

Delgado, R., \& Stefancic, J. (2000). Califórnia's racial history and constitutional rationales for race-cosncious decision making in higher school. UCLA Law Review, 47(6), 1521-1552.

Detterman, D. K. (2000). Tests, affirmative action in university admissions, and the American way. Psychology, Public Policy, and Law, 6, 44-55.

Ferreira, N. S. A. (2002). As pesquisas denominadas "Estado da Arte". Educação e Sociedade, 23(79), 257-272.

Fry, P., \& Maggie, Y. (2004). A reserva de vagas para negros nas universidades brasileiras. Estudos avançados - Dossiê: O negro no Brasil, 18(50), 67-80.

Goergen, P. O. (2005). Pós-modernidade, ética e educação: Polêmicas do nosso tempo. Campinas, SP: Autores Associados.
Guinier, I (2003, July 2-8). Saving affirmative action and a process for elities to choose elites. Village Voice, 1-5.

Gurin, P., Dey, E. L., Hurtado, S., \& Gurin, G. (2002). Diversity and higher education: Theory and impact on educational outcomes. Harvard Educational Review, 72(3), 330-366.

Gurin, P., Nagda, B. A., \& Lopez, G. E. (2004) The benefits of diversity in education for democratic citizenship. Journal of Social Issues, Malden, 60(1), 17-34.

Hoffman, J. L., \& Lowitzki, K. E. (2005). Predicting college success with high school grades and Test Scores: Limitations for minority students. The Review of Higher Education, 28(4), 455-474.

Htun, M. (2004). From "Racial Democracy" to "Affirmative Actions": Changing state policy on race in Brazil. Latin American Research Review, 39(1), 60-89.

Ianni, O. O. (2004a). O preconceito racial no Brasil. Estudos avançados - Dossiê: O negro no Brasil, 18(50), 6-20.

Ianni, O. O. (2004b). Dialética das relações raciais. Estudos avançados - Dossiê: O negro no Brasil, 18(50), 21-30.

Iygun, M. F., \& Levin, A. T. (2003). What determines public support for afirmative action? Southern Economic Journal, 69(3), 612627.

Journal Store. (2000). About Jstor. Retirado em 20 maio 2005, de http://www.jstor.org/about

Long, B. T. (2003). Diversity by any other name: Are there viable alternatives to affirmative actions in higher education? Western Journal of Black Issues Studies, 27(1), 30-34.

Maffesoli, M. (2002). O tempo das tribos: O declínio do individualismo nas sociedades de massa (3. ed.). Rio de Janeiro, RJ: Forense.

Massey, G. (2004). Thinking about affirmative action: Arguments supporting preferencial policies. Review of Policy Research. Georgetown, 21(6), 783-797.

Melo-Silva, L., Lassance, M. C. P., \& Penna, D. H. S. (2004). A orientação profissional no contexto da educação e trabalho. Revista Brasileira de Orientação Profissional, 5(2), 31-52.

Ministério da Educação (2006). Projeto de Lei 3627/2004. Brasília, DF: Autor. Retirado em 23 abr. 2006 de http://portal.mec.gov.br/ arquivos/pdf/ref_projlei3627.pdf

Moehlecke, S. (2004a) Fronteira da igualdade no ensino superior: Excelência e justiça social. Tese de Doutorado não-publicada, Faculdade de Educação, Universidade de São Paulo, SP.

Moehlecke, S. (2004b) Ação afirmativa no ensino superior: Entre a excelência e ajustiça social. Educação \& Sociedade, 88(25), 757776. Retirado em 25 nov. 2005, de http://www.scielo.br/scielo.php? pid=S010173302004000300006\&script=sci_arttext\&tlng=pt

Pena, S. D. J., \& Bortolini, M. C. (2004). Pode a genética definir quem pode se beneficiar das cotas universitárias e demais ações afirmativas? Estudos avançados - Dossiê: O negro no Brasil, $18(50), 31-40$.

Potiguara, E. (2002). Participação dos povos indígenas na Conferência em Durban. Revista Estudos Feministas, 10(1). Retirado em 28 jun. 2006, de http://www.scielo.br/scielo.php?script= sci_arttext\&pid=S0104026X200200010001 6

Rhoads, R. A., Saenz, V., \& Carducci, R. (2005). Higher education reform as a social movement: The case of affirmative action. The Review of Higher Education, 28(2), 191-220.

Sonn, C., Bishop, B., \& Humphries, R. (2000). Encounters with de dominant culture: Voices of indigenous students in Mainstream higher education. Australian Psychologist, 35(2), 128-135. 
Strey, M. N., Jacques, M. G. C., Bernardes, N. M. G., Guareschi, P. A., Carlos, S. A., \& Fonseca, T. M. G. (1998). Psicologia social contemporânea: Livro-texto. Petrópolis, RJ: Vozes.

Universia Brasil (2002). Definição de cotas na Ufes acontece quarta. São Paulo, SP: Autor. Retirado em 28 nov. 2005, de http:// www.universia.com.br/noticia/materiacli pping.jsp?not=30132

Welsh, J. F. (2004). Supporting minority access and achievement: Is there a role the State? Race Ethnicity and Education, 7(4), 385-399.

Wightman, L.F. (2000). The role of standardized admissions tests in the debate about merit, academic standards, and Affirmative Action. Psychology, Public Policy, and Law, 6, 90-100.

Wolff, R. P., \& Wolff, T. P. (2005). The pimple of Adonis's Nose: A dialogue on the concept of merit in the affirmative action debate. Hastings Laws journal, 56(3), i-lxiii.

Zamani, E. M., \& Brow, C. M., II (2003). Affirmative action in postsecondary educational settings: The historic nexus of meritocracy and access in US Higher Education. International Association of Universities [IAU]. Higher Education Policy, 16(1), 27-38.

Fernanda Vieira Guarnieri é graduada em Bacharelado e Formação de Psicólogo pela Faculdade de Filosofia, Ciências e Letras de Ribeirão Preto, Universidade de São Paulo (FFCLRP - USP). É aluna de mestrado do departamento de Psicologia e Educação da FFCLRPUSP e bolsista FAPESP. Membro da equipe técnica de editoração da Revista Brasileira de Orientação Profissional (RevBOP) e integrante do Grupo de Pesquisas em Psicodiagnóstico (CPP). Endereço para correspondência: Rua Visconde do Rio Branco, 761, 33 a andar, Ribeirão Preto, SP, 14015-000. Telefone: (16) 8118-8684. fervigua@pg.ffclrp.usp.br
Lucy Leal Melo-Silva é Professora Doutora do Departamento de Psicologia e Educação da FFCLRPUSP. Responsável pelas disciplinas e estágios da área da Orientação Profissional. Coordenadora do Programa Vita, do Serviço de Orientação Profissional (SOP), integrante do Centro de Pesquisas em Psicodiagnóstico (CPP), membro do Conselho Diretor do Centro de Psicologia Aplicada (CPA), programas e órgãos da FFCLRP-USP. Membro da Associação Brasileira de Orientadores Profissionais (ABOP), da Sociedade Brasileira de Psicologia (SBP) e da International Association Educational Vocacional Guidance (IAEVG). Editora da RevBOP. Doutora em Psicologia pela USP. Mestre em Educação Especial pela Universidade Federal de São Carlos (UFSCar). Especialista em Reabilitação Profissional pela Fundação Educacional de Bauru (atual UNESP). Especialista em Grupo Operativo pelo Instituto de Psicologia Social "Enrique Pichon-Rivière" de Ribeirão Preto. Endereço para correspondência: Av. Bandeirantes, 3900, Bairro Monte Alegre, Ribeirão Preto, SP, 14040-901. Telefone: (16) 3602-3789. lucileal@ffclrp.usp.br

\section{Ações afirmativas na educação superior: rumos da discussão nos últimos cinco anos}

Fernanda Vieira Guarnieri e Lucy Leal Melo-Silva

Recebido: 24/10/2006

$1^{\text {a }}$ revisão: 06/03/2007

Aceite final: 10/04/2007 